\title{
The Role of Smart Farming in Sustainable Development
}

\author{
Siti Fatimahwati Pehin Dato Musa, Universiti Brunei Darussalam, Brunei \\ iD https://orcid.org/0000-0003-1987-4595 \\ Khairul Hidayatullah Basir, Universiti Islam Sultan Sharif Ali, Brunei \\ iD https://orcid.org/0000-0001-5858-4916 \\ Edna Luah, AgroBIZ, Brunei \& LiveWIRE Brunei, Brunei \\ iD https://orcid.org/0000-0002-8264-949X
}

\begin{abstract}
This paper intends to explore the development of agriculture into smart farming and how smart farming can contribute to the sustainable development goals. The paper focuses on how smart farming can be imparted in sustainable agriculture by analyzing the environmental, economic, and social impact. This paper applied a systematic literature review technique to assess published academic literature on smart farming and sustainable agriculture in Southeast Asia. The review identified that smart farming can lead to less environmental damage, lower cost, and higher productivity and has the potential to create decent jobs for the youth, ultimately leading to a sustainable food system.
\end{abstract}

\section{KEYWORDS}

Agritech, ASEAN, Food Security, Internet of Things (IoT), Precision Agriculture, Sustainable Development Goals (SDGs), Sustainable Intensification, Systematic Literature Review

\section{INTRODUCTION}

Food security has always been a challenge in the Southeast Asia region. According to MarzędaMłynarska (2017), this is due to the growing population, challenging environmental conditions, risks of climate change, and rapid urbanisation. The definition of food security has evolved; in 2002, it was redefined as a situation that exists when all people, at all times, have physical, social and economic access to sufficient, safe and nutritious food that meets their dietary needs and food preferences for an active and healthy life (FAO, 2002).

The current pandemic of COVID-19 has resulted in a new dimension of food (in)security i.e. the disruption of supply and demand. This is mainly due to the lockdown of several major cities, border closures, and job or income losses. This has disrupted the food supply chain and affected the status of food security in many countries. COVID-19 has resulted in an abrupt change in the world's food consumption and production patterns which is a reflection that nature has a limited capacity to meet human needs. Human activities have been responsible for the crossover of zoonotic diseases like SARS, MERS and COVID-19. The hunting and handling of wild animals for the exotic food market has presented the opportunity for cross-species transmission of infectious diseases. Episodes of avian flu (H5N1) and swine flu (H1N1) outbreaks originating from densely packed farms of hybrid

DOI: 10.4018/IJABIM.20220701.oa5

This article published as an Open Access article distributed under the terms of the Creative Commons Attribution License (http://creativecommons.org/licenses/by/4.0/) which permits unrestricted use, distribution, and production in any medium, provided the author of the original work and original publication source are properly credited. 
livestock have also shown that modern farming practices have shaped our disease ecology (Wallace, 2016). Suffice to say, humanity's increasingly exorbitant consumption patterns have contributed to this instability. To prevent another pandemic that is as damaging as or worse than the one presently raging, the world urgently needs to prioritize more sustainable patterns of food production and consumption.

Sustainability has been discussed globally through the concept of sustainable development. The World Commission on Environment and Development (1987) defines sustainable development as 'development that meets the needs of the present without compromising the ability of future generations to meet their own needs" (United Nations, 1987). Having a sustainable approach is considered an important goal today due to the fast population growth whereby the world's population is expected to reach nearly 10 billion which is an increase by more than $30 \%$ by 2050 (from 7 billion in 2011) (FAO, 2017). This puts a strain on the world's agricultural resources especially on the land as higher yields are expected without considering the damage to the environment (Gil, et al., 2019). These trends threaten the sustainability of agricultural systems and undermine the global capacity to meet its needs. To ensure enough food is produced for a population of nearly 10 billion by 2050 without critically degrading natural resources, a transition to a smart and sustainable agricultural system is needed.

In a way, the pandemic also provides farmers and researchers the opportunity to reconsider their current approaches to agriculture and reinvent farming using greener techniques. The agritech scene in Southeast Asia is still in its early stages and just starting to expand; it is helping farmers to implement more resilient, productive and sustainable agricultural practices. However, regulatory hurdles and a digital divide especially in developing countries have stood in the way of the smooth adoption of smart farming methods. It is possible that this pandemic may become the catalyst that sets in motion smart farming in Southeast Asia.

Incidentally, COVID-19: the biggest crisis of this century has coincided with the Fourth Industrial Revolution (4IR) whereby new technologies like artificial intelligence (AI), Big Data, Blockchain and the Internet of Things (IoT) among others have altered the way in which people live, work and interact. Likewise, these new technologies also have the power to transform the food supply chain for the better as can be seen from trials and implementations abroad.

The objectives of this paper are twofold. First, it attempts to explore the changing global trend in agriculture which involves digital transformation in line with the industrial revolution. Secondly, this paper attempts to convince that smart farming could be the answer to sustainable food production and contribute towards achieving a number of the sustainable development goals (SDGs).

\section{METHODOLOGY}

This paper applies systematic literature review in an attempt to seek out the existing knowledge and research gaps on the subject matter. The five steps of conducting a systematic literature review put forward by Zimmerman et al. (2016) was used. The five steps are as follows: (1) formulating review questions, (2) searching for materials, (3) evaluating and selecting, (4) analysing and synthesising, and (5) reporting review results.

The research question of this study is how can smart farming be incorporated in to sustainable agriculture and contribute towards the 2.4.1 Sustainable Development Goal (SDG) Indicator? To identify a relevant set of articles concerning the research questions, criterion sampling based on keyword searches was applied. A number of keyword combinations were used to search for the articles from leading databases like Web of Science and Scopus. The search terms included smart farming, agritech, precision farming, information and communication technology (ICT) based farming and ASEAN and Southeast Asia, sustainable agriculture and sustainable development goals.

The database search resulted in 109 articles in the social science criteria. Articles that solely focused on technical issues or did not report results of empirical studies were excluded. This abstract screening resulted in a total of 13 relevant articles, which were subsequently analysed with respect to sustainability and smart farming in Southeast Asia. Due to the limited number of relevant articles, an 
extensive desk research was conducted which includes reports and other grey literatures to do with smart farming in Southeast Asia.

After evaluating and selecting the most suitable articles and reports for review, the next step is to analyse and synthesise the selected materials. The aim of the analysis stage is to assess and analyse the selected paper independently and synthesise the evidence of the intended factors (smart farming and sustainable agriculture) (Denyer and Tranfield, 2009). Following closer analysis, the articles were then categorized based on the research questions to create a structure for this review. This review forms the basis for the conclusion of this research and its recommendations for addressing the current gaps in knowledge.

\section{TRANSITION TO SMART FARMING}

The urgency to achieve food security has always been whether or not we could feed the 9 billion of the world population. Malthus in his work on Population: The First Essay (Arbor, 1957) highlighted that population grows geometrically the output of food grows arithmetically which will inevitably result in the scarcity of food. Most of the literatures in smart farming are technical and explains the importance of technology in food production. Literatures on smart farming in the social sciences are still lacking especially on the impact of digital transformation in agriculture on farmers and society. For instance, Santiteerakul et al. (2020) investigated how technology applications could help farmers to utilize appropriate data in their decision-making which can lead to the use of low-input agriculture. Walter et al. (2017) studied technical improvement through the use of ICT in agriculture including the challenges of property rights on the owner and use of data. Further, Klerkx et al. (2019) in his review of social science literatures on digital agriculture, smart farming and agriculture 4.0 and suggested that one of the emerging cluster which needs to be given more emphasis is digitally enabled agricultural transition pathways.

As technology is embedded in the agricultural sector, this raised a question of whether agriculture is still regarded as a traditional sector. Advanced countries like Japan and The Netherlands have utilized technology in their farming which is in line with the fourth industrial revolution which coincidentally supports the SDGs, particularly the ${ }^{\text {th }}$ SDG to 'build resilient infrastructure, promote inclusive and sustainable industrialization and foster innovation'. Thus, this link needs to be explored especially its potential to meet the global demand and for countries to be self-sufficient especially when there is unprecedented crisis, for instance the COVID-19 pandemic.

The digital transformation is exciting and fast-moving including agriculture. Walter et al. (2017) suggested that agriculture is undergoing a fourth revolution as a result of the exponentially increasing use of ICT in agriculture. The fourth industrial revolution is a popular term and remains a growing interest in many countries. However, agricultural revolution is yet to be explored. As agriculture is undergoing a new technology revolution, it should not be overlooked. The summary of agricultural revolution can be seen in Table 1 .

From the table above, it can be seen the transition of farming from traditional to the use of latest and advanced technologies. Undeniably, technology has changed the practice in agriculture, making the food and agricultural systems more productive, profitable and sustainable.

Farming with the use of new technologies has always been associated with smart farming. Pivoto et al. (2018) explained smart farming as the incorporation of information and communication technologies into machinery, equipment, and sensors for use in agricultural production systems. Sensors plays an important tool in Smart Farming. In addition, Fountas et al. (2015) claimed that smart farming will help to reduce the impacts of climate change by keeping them constant or reduce production costs in agricultural activities and minimize environmental constraints. The emergence of smart farming is due to the rapid development of Internet of Things (IoT) and cloud computing (Sundmaeker et al., 2016). New technologies such as the IoT and cloud computing are expected to advance this development, introducing more robots and artificial intelligence into farming (Pivoto et 
Table 1. Agricultural Revolution

\begin{tabular}{|l|l|}
\hline The first agricultural revolution & Occurred when humans started farming around 12,000 years ago. \\
\hline The second agricultural revolution & $\begin{array}{l}\text { The reorganisation of farmland from the 17th century onwards that followed } \\
\text { the end of feudalism in Europe. }\end{array}$ \\
\hline $\begin{array}{l}\text { The third agricultural revolution } \\
\text { (also known as the green revolution) }\end{array}$ & $\begin{array}{l}\text { The introduction of chemical fertilisers, pesticides and new high-yield crop } \\
\text { breeds alongside heavy machinery in the 1950s and 1960s. }\end{array}$ \\
\hline $\begin{array}{l}\text { The fourth agricultural revolution } \\
\text { (much like the fourth industrial } \\
\text { revolution) }\end{array}$ & $\begin{array}{l}\text { The anticipated changes from new technologies, particularly the use of } \\
\text { Artificial Intelligence (AI) to make smarter planning decisions and power } \\
\text { autonomous robots. Such intelligent machines could be used for growing and } \\
\text { picking crops, weeding, milking livestock and distributing agrochemicals via } \\
\text { drone. }\end{array}$ \\
\hline
\end{tabular}

Source: Rose and Chivers (2020)

al., 2019). The term of agritech is also exchangeably used which refers to the use of technology and technological innovation to improve the efficiency and output of agriculture.

\section{SUSTAINABLE AGRICULTURE}

The United Nations SDG includes the promotion of sustainable agriculture in goal 2: zero hunger end hunger, achieve food security and improved nutrition and promote sustainable agriculture. Now, more than ever, with scarce natural resources depleting, inevitable consequences of climate change and growing global population, agriculture must be sustainable to ensure achievement of SDG 2 and enough food for all in the future (United Nations, 2020). Due to the environmental stress on water scarcities, insufficient land use, soil depletion, and greenhouse gas emissions, the demands on sustainable agriculture are rapidly increasing (Santiteerakul, et al., 2020). The term "sustainable agriculture" refers to an agricultural system that will continue to be productive in the future (Feenstra, 2020). The main objectives of sustainable agriculture are to incorporate a healthy environment, economic profitability, and social and economic equity into the production process (FAO, 2019). The indicators of sustainable agriculture provided by the United Nation SDGs called the SDG Indicator 2.4.1 are measured in three different perspectives; economic, environmental and social terms. The economic perspective includes land productivity, profits and resilience; environmental in terms of soil profile, water usage, fertilizer and pesticide usage and biodiversity; and social in terms of employment opportunities, food security and land tenure (FAO, 2019). Indicator 2.4.1 reflects the multiple dimensions of sustainability: economic, environmental and social. A set of 11 sub-indicators are defined, organised in themes, each mapped to one of the three dimensions as shown in table 2.

The next section discusses how smart farming can be imparted as part of sustainable agriculture. This is done by analysing the environmental, economic and social impact of smart farming in Southeast Asia.

\section{Environmental Impact}

Many current farming practices damage the environment and are a major source (19-29\%) of anthropogenic greenhouse gas (GHG) emissions such as carbon dioxide and nitrogen dioxide (Campbell, et al., 2014). Smart farming comes with so many opportunities with the aim of reducing ecological footprint.

In tackling environmental issues in agriculture, precision agriculture (PA) can help in managing crop production inputs in an environmentally friendly way. There are various definitions of precision agriculture. Kubota Corporation (2020) defined precision agriculture as a farm operation technique aimed at minimizing costs for fertilizers, chemicals, water, and fuel and maximizing yields by utilizing 
Table 2. SDG Indicator 2.4.1

\begin{tabular}{|l|l|l|l|}
\hline \multicolumn{1}{|c|}{ Dimensions } & \multicolumn{1}{|c|}{ No } & \multicolumn{1}{c|}{ Theme } & \multicolumn{1}{c|}{ Sub-indicators } \\
\hline \multirow{5}{*}{ Economic } & 1 & Land productivity & Farm output value per hectare \\
\cline { 2 - 4 } & 2 & Profitability & Net farm income \\
\cline { 2 - 5 } & 3 & Resilience & Risk mitigation mechanisms \\
\hline \multirow{5}{*}{ Environmental } & 4 & Soil health & Prevalence of soil degradation \\
\cline { 2 - 5 } & 5 & Water use & Variation in water availability \\
\cline { 2 - 5 } & 6 & Fertillizer pollution risk & Management of fertillizers \\
\cline { 2 - 4 } & 7 & Pesticide risk & Management of pesticides \\
\cline { 2 - 4 } & 8 & Biodiversity & Use of biodiversity support practices \\
\hline \multirow{5}{*}{ Social } & 9 & Decent employment & Wage rate in agriculture \\
\cline { 2 - 4 } & 10 & Food security & Food insecurity experience scale (FIES) \\
\cline { 2 - 4 } & 11 & Land tenure & Secure tenure rights to land \\
\hline
\end{tabular}

Source: Food and Agriculture Organisation, 2019

data. It also aims to improve the taste and quality of agricultural products, ensure traceability, hand down knowhow, and reduce heavy labor. For instance, The Netherlands is another small and densely populated country known for advanced initiatives in precision farming and it is the second largest exporter of agricultural produce after the U.S (Viviano, 2017). The Netherlands has become the world leader in agricultural innovation, pioneering new paths to fight hunger. PA is bringing the most modern technology, like never seen before in agricultural fields. A combination of techniques can assess the quality of individual plants and determine exactly how much water and nutrients they need to receive. Some agritech farms implemented by the Netherlands are as follows: i) climate-controlled farms which grow crops around the clock and in every kind of weather; ii) developing technology to maximize poultry production while ensuring humane conditions; and iii) indoor LED-light crops (Viviano, 2017).

Singapore demonstrates a good example in its efforts to embrace smart farming and agritech. Singapore is a small and densely populated with lack of natural resources with less than 1 per cent of its land dedicated to agriculture, thus most of their food are imported. Singapore has come up with technological innovations and ingenious new agricultural methods in its effort to become Asia's urban agri-food tech hub. Among the technology imparted in agriculture in Singapore are (i) IoT data analytics which farms to control environmental conditions such as light and irrigation to track temperature, humidity, and the growth of crops; (ii) Automated systems such as autofeeders; automated pump systems and shed-cleaning bots reduce the need for manual labour and (ii) Hydroponics system eliminating the need for pesticides and fertilisers, while optimising the nutritional value of harvested plants (Ai Kok, 2020).

Thailand has also implemented technology use of multiple sources for farming efficiency. This was not just for generating the highest optimum yield with the least amount of resources but also incorporating conscious use of smart technologies to generate lesser carbon footprint with biomass conversion technologies such as the implementation of solar energy, biomass energy and greenhouse dryers (Mastoi, et al., 2014). This is in-line with the commitment of net-zero gas emissions efforts by the year 2050 by the International Energy Agency, whereby the National Energy Policy Commission of Thailand has pledged in 2013 to support solar installations by the following year (International Energy Agency, 2018).

Wangree Health Factory Company in Thailand uses modern digital technology to supply fresh organic vegetables and fruits to the Thai market. It uses artificial intelligence light for its indoor 
farming system connected with a smart control system. The system results in high-quality and highyield production year-round under a controlled environment. In addition, the IoT-based technologies allow farmers to plan their production by using mobile devices for monitoring and controlling their farming systems. The growth process is fully automated for watering, lighting, nutrient adding, and temperature controlling. The $173.85 \mathrm{~m} 2 \times 6 \mathrm{~m}$ high plant factory produces approximately 50,552 heads of lettuce per month (Santiteerakul, et al., 2020).

The use of smart farming in the case of Wangree Health Factory Company in Thailand have resulted in effective resource use efficiency in terms of water use and land use. Less water is needed due to a water control system that reduces drained water in the growing area and recycles water vapor into liquid water. It also increases land use efficiency. As the vertical farming method provides a 99 per cent reduction in land use (Santiteerakul, et al., 2020).

\section{Economic Impact: Profitability and Resilience}

Smart farming has the potential in making agriculture more profitable and sustainable by reducing resource inputs and cost. The use of certain techniques to reduce resource inputs can ensure that farmers save immensely on labour and the need for reliable spatial data in risk reduction. This is attributable to the fact that smart farming encourages the use of technology in site-specific weather forecasts, probability mapping of disasters and diseases, and yield projections. According to Pivoto et al. (2018) sensors, electrotechnical devices, used in smart farming measure physical quantities from the environment and convert the measurements into a signal which can be read by an instrument.

Agritech is also expected to boost productivity. The new technologies with artificial intelligence, analytics, connected sensors, and other emerging technologies could further increase yields, improve the efficiency of water and other inputs, and build sustainability and resilience across crop cultivation and animal husbandry (Godde et al., 2020). Furthermore, agritech aims at maximising yields with fewer input and environmental costs. Not only that, the agritech will also enable the farmers to get connected with potential consumers directly, thus, shortening the supply chain. In order to make this happen, diverse stakeholders will be involved - farmers, government, tech providers and researchers - to build digital tools that respond to local challenges.

Food producers and scientists are also using and developing new technologies to support PA. With Big Data, smallholders can make better and more informed decisions on for instance, planting or harvesting times. With PA, the execution of the work like the application of seeds, water, fertilisers, and crop protection products becomes more efficient. The use of drones has also been recommended for the monitoring of crops and spraying of pesticides more efficiently.

Site-specific information also enables new insurance and business opportunities for the entire value chain, from technology and input suppliers to farmers, processors, and the retail sector in developing and developed societies alike. If all farming-related data are recorded by automated sensors, the time needed for prioritising the application of resources and for administrative surveillance is decreased. Digital business models have also emerged, including peer-to-peer lending (Pucci, 2020). Agrifinance is an emerging subsector that helps rural and vulnerable smallholders to reduce risks and increase farm investment so that they can increase yields and earn a higher income. Apart from government investment and lending, governments can look into further developing this area of agrifinance to give farmers the opportunity to afford appropriate new smart farming technologies for their day-to-day operations.

The adoption of IoT is expected to grow considerably in Malaysia with the arrival of 5G technology. The Malaysian Communications and Multimedia Commission recognized that 5G enabled precision farming will be the next smart farming platform featuring an AI-driven automation platform that allows predictive growth modelling, remote global monitoring and control, thus, making farming possible anywhere (Sharon, 2020). This also promotes usage of internet by agripreneurs to be better informed on the methods that has already been tested and shared on the internet which makes it more cost efficient. Online resources such as mobile applications can help on precise planning, 
implementation and data collection of their resources and produce. The usage of ICT by the local agripreneurs in Malaysia empowers them to create a network amongst the others in the agri-based industry. Agripreneurs in Malaysia use website surfing extensively as their resource avenue to gather information on product and services which in turn facilitate communication across other industry players such as other agripreneurs, agri-technicians, extension officers and agencies.

The implementation of biotechnology and agrotechnology that are currently and widely used in Malaysia aims to improve yields, reduce cost and reduce losses. Modern chemical herbicides and Integrated Pest Management techniques are also implemented to the modern farming scheme in Malaysia. The local farmers also have recognised the benefits of agrotechnology and have utilised it to maximise resources, manpower and better productivity at large, especially to farmers at rural areas to lift them out of poverty. HAVVA Agrotech Sdn Bhd in Malaysia is a company that combined smart farming (planting) methods, such as hydroponic, aquaculture, vertical farming, vermiponic and aeroponic, and transpired them into urban farming, making farming accessible and simplified for city-dwellers (Loo, 2020). Urban farming is encouraged to inspire many to grow from own homes and small gardens. These methods also fully optimise space and introduces many varieties of plants in a limited space compared to traditional farming.

The Philippines introduced the Smart Plant Production in Controlled Environment (SPICE) programme aimed at boosting sustainable farming, reducing climate impact and increasing yields and returns. Beyond the objectives of local food security, the programme also targets to make available business opportunities for the local vendors in terms of providing services in the agri-sector (Oxford Business Group, 2018). Vietnam, where agri-industry remains a major source of employment is also working to boost the industry using integrated farming technologies. It is projected that the industry will account for double the current share and will contribute to one-fourth of the country's GDP with the use of smart farming (World Bank, 2016).

\section{Social Impact: Decent Employment for More Youth Involvement}

Smart farming also has the potential to boost youth involvement in agriculture. In pursuing the fourth industrial revolution and 'agriculture 4.0', social impact as a result of the new technologies need to be taken into account. Rose et al. (2021) suggested that agriculture 4.0 should be guided by the concept of sustainable intensification (SI) for the benefits are enjoyed by people, production and the planet. An important issue which needs to be addressed is the ageing farmers. This is a worldwide phenomenon including countries in ASEAN therefore, getting the youth involved in farming is crucial. These emerging new technologies can help demonstrate to youth that agriculture can be a viable and profitable business opportunity which can increase the desirability of agriculture-related careers. Engaging youth in agriculture will enable them to bring innovative and tech-savvy perspective to solving some of the most difficult problems in agriculture.

Thailand was the first Southeast Asian nation to adopt agriculture biotechnology. Thailand is currently facing a farming society that is ageing and has constantly been working to attract more youth into the agriculture sector. In its effort to encourage youth in playing a bigger part in the main commodity trade of the country, the Department of Agricultural Extension has set up a 'Young Smart Farmer' programme to elevate the youth in the agronomic networks to replace over 50 percent of retired farmers. The initiative aims to produce new agricultural 'young blood' to achieve maximum agricultural capability by engaging technology to improve yields, as well as other commercial aspects, including production capacity, management and farm marketing (Bangkok Post, 2019). The Department recognized the importance of implementing digital technologies, such as the digitalized cultivation to improve quality of yield so that to create an inclusive means for increasing profits, whether for local consumption or for exports. Digitized cultivation ensures that natural resources are used with precision to minimise cost and prevent the possibilities of wastage.

Similarly, Brunei in its bid to attract more youth into the agriculture sector has started to adopt smart farming. With the ease and availability of the internet, youth in Brunei becomes more well- 
informed of modernisation in agriculture. The presence of the internet helps them learn approachable methods to start experimenting small farm systems from the comfort of their own homes. One example is S\&R Aquafarm (Musa, et al., 2020). The founder of S\&R Aquafarm is an inspiring youth who built an aquaponic farm that aims to promote sustainable smart farming. The farm preserves environmental amenities by utilizing clean energy, emitting lesson carbon and reducing water wastage. This farm is powered by solar energy and recycling water containing waste from fish as feed for the hydroponics demonstrating that smart farming is possible, feasible and sustainable even with limited space.

Agribusiness start-ups founded by youths started to develop rapidly in Brunei to provide agricultural solutions using smart farming methods and technologies such as precision-farming softwares, censors and machineries. One example is Agrome IQ, a Brunei's startup agritech. The technologies and tools help agripreneurs collect information and analytics to better round their business decisions affecting yield. They utilise technology to simulate scenarios and case studies references before implementation for a more predictive and precise outcome. The COVID-19 pandemic outbreak led to Agrome IQ to launch Brunei's first online marketplace for local farmers to sell directly to their potential customers. The motivation to launch the platform was to address the challenges facing smallholder farmers in marketing their produce amidst the COVID-19 crisis. The data obtained from purchases also help in gauging customers' demand, and is shared with farmers to help them better plan which crops to be planted in the future (Wong, 2020). Thus, this helps to optimise the supply chain for the farmers when they struggle to market their produce.

Another platform to increase youth participation in agriculture in Brunei is through AgroBIZ. In 2019, AgroBIZ was formed as a project under Brunei Shell Petroleum (BSP) with its social investment platform, LiveWIRE Brunei. BSP signed a memorandum of understanding with Institute of Brunei Technical Education which, aimed to boost the interest and knowledge of youth in agropreneurship and in the field of agro-technology as agro-technicians. By incorporating the youth into the AgroBIZ project, they learn skills, knowledge and gain expertise in their field of study to raise the rice and other cash-crop sufficiency in Brunei (Shell LiveWIRE Brunei, 2019). This helps the local education system come to a fuller circle of promoting education for agro-farming, where not just researches are being conducted but also implementation avenues for students to form better concept, experience and skill set for their future farm and technical trade in agro-technology. Another main commitment of AgroBIZ is to reduce carbon footprint and environmental impact. Incorporating ecology to ward off pests with the least environmental damage, crops are administered with natural pesticides and natural fertilizers to encourage healthy yield while also to prevent damage to the environment.

It can be observed that countries in ASEAN have developed numerous agritech startup initiatives in order to get more youth involved in agriculture sector. The modernisation of agriculture due to the rapid development of IoT and cloud computing has transformed the perception of agriculture from working under the scorching sun and manual labour to working on their fingertips in a controlled environment.

\section{LIMITATION AND FUTURE RESEARCH}

One of the limitation of this study is that it is a purely theoretical paper. This paper have explored the latest trend of agriculture and the adoption of smart farming methods in contributing towards sustainable agriculture to meet SDGs and the growing global food demand. The source of information and data in this paper are mostly secondary hence future studies should consider the use of primary data and observation which will shed more light on related issues through in-depth empirical and observable evidence. 


\section{CONCLUSION}

The world has been facing challenges in feeding the increasing population. This has prompted the agriculture sector to come up with innovative ways on how to produce in high quantity and quality. The unprecedented crisis, COVID-19, have led to disruptions in the supply chain which further challenge the agriculture sector. One of the ways to tackle this issue is by helping the farmers to be more connected through smart farming. Smart farming offers a path toward sustainable agriculture by providing innovative ways into a profitable, socially accepted agriculture that benefits the environment, sustain farmers' income and resilience and attract more youth into the sector.

Among the barriers for many of Southeast Asia's smallholders is the lack of capital to finance smart farming, hence more intervention is needed in this area. The challenge is to ensure that revolution works for everyone, especially small-scale farmers. This can be done by conducting capacity building among farmers in order to avoid deepening the digital divide and ensuring a concise ecosystem is in place to support healthy growth and support for the relevant stakeholders in the agriculture industry.

It has to be noted the transformation of agriculture in to smart farming in Southeast Asia will take some time as the nature of the sector is different and it was once a traditional sector. Issues such as communicating with older farmers, who could often not understand the technicalities of new technologies will also need to be addressed. However, with the rapid industrial revolution, every player in different industries will eventually need to embrace and adopt the change. 


\section{REFERENCES}

Ai Kok, M. (2020). Singapore's Emerging AgriTech Ecosystem. UNDP Global Centre for Technology, Innovation and Sustainable Development. Retrieved from: https://sgtechcentre.undp.org/content/sgtechcentre/en/home/ blogs/sg-agritech-ecosystem.html

Arbor, A. (1957). Malthus, T. Robert: Population: The First Essay. University of Michigan Press.

Bangkok Post. (2019). Young Smart Farmers Growing Thailand's Upward Economic Trend. Bangkok Post. Retrieved from: https:/www.bangkokpost.com/thailand/pr/1710127/young-smart-farmers-growing-thailandsupward-economic-trend

Campbell, B. M., Thornton, P., Zougmoré, R., van Asten, P., \& Lipper, L. (2014). Sustainable intensification: What is its role in climate smart agriculture? Environmental Sustainability, 8, 39-43.

Denyer, D., \& Tranfield, D. (2009). Producing a Systematic Review. In D. A. Buchanan \& A. Bryman (Eds.), The SAGE Handbook of Organizational Research Methods (pp. 671-689). Sage.

Feenstra, G. (2020). What is Sustainable Agriculture? University of California. Retrieved from https://sarep. ucdavis.edu/sustainable-ag

Food and Agriculture Organization (FAO). (2002). The state of food insecurity in the world 2001. FAO.

Food and Agriculture Organization (FAO). (2017). The Future of Food and Agriculture Trends and Challenges. FAO.

Food and Agriculture Organization (FAO). (2019). Sustainable Development Goals Working for Zero Hunger. FAO.

Fountas, S., Carli, G., Sørensen, C. G., Tsiropoulos, Z., Cavalaris, C., \& Vatsanidoud, A. (2015). Farm management information systems: Current situation and future perspectives. Computers and Electronics in Agriculture, 115, 40-50. doi:10.1016/j.compag.2015.05.011

Garnett, T., Appleby, M. C., Balmford, A., Benton, T. G., Bloomer, P., \& Burlingame, B. (2013). Sustainable intensification in agriculture: Premises and policies. Science, 341(6141), 33-34. doi:10.1126/science.1234485 PMID:23828927

Gil, J. D. B., Reidsma, P., Giller, K., Todman, L., Whitmore, A., \& van Ittersum, M. (2019). Sustainable development goal 2: Improved targets and indicators for agriculture and food security. Ambio, 48(7), $685-698$. doi:10.1007/s13280-018-1101-4 PMID:30267284

Godde, L., Katz, J., Ménard, A., \& Revellat, J. (2020). Agriculture's connected future: How technology can yield new growth. Retrieved from: https://www.mckinsey.com/industries/agriculture/our-insights/agriculturesconnected-future-how-technology-can-yield-new-growth

International Energy Agency. (2018). World Energy Outlook Report. Retrieved from: https://www.iea.org/ reports/world-energy-outlook-2018

Klerkx, L., Jakku, E., \& Labarthe, P. (2019). A review of social science on digital agriculture, smart farming and agriculture 4.0: New contributions and a future research agenda. NJAS Wageningen Journal of Life Sciences, 100315. Advance online publication. doi:10.1016/j.njas.2019.100315

Kubota Corporation. (2020). What is Precision Farming? Retrieved from: https://www.kubota.com/global-index/ precision-farming/01.html

Marzęda-Młynarska, K. (2017). Food Security Governance in the Southeast Asia Region: From National to Regional Governance. Historia i Polityka, 20(27), 31-48. doi:10.12775/HiP.2017.010

Mastoi, Q., Abdul Rahman, I., \& Dahlan, A. (2014). Agro-tech in Malaysia and Literature Review Knowledge Sharing from Agro-Technology Using Nations: 4.1. Technology usage for Agriculture in Thailand - Biomass Dryers, Solar energy and Greenhouse Dryers. Retrieved from: https://www.ijser.org/researchpaper/Agro-techin-Malaysia-and-Literature-Review-Knowledge.pdf 
Musa, S. F. P. D., Idris, D. S. R., \& Basir, K. H. (2020). Exploring the Motivations and Challenges of Agripreneurs: A Case Study of Brunei Darussalam. In Economics, Business, and Islamic Finance in ASEAN Economics Community. doi:10.4018/978-1-7998-2257-8

Oxford Business Group. (2018, May 24). New smart farm to help the Philippines achieve sustainable agriculture goals. Retrieved from https://oxfordbusinessgroup.com/news/new-smart-farm-help-philippines-achievesustainable-agriculture-goals

Pivoto, D., Waquil, P. D., Talamini, E., Finocchio, C. P. S., Dalla Corte, V. F., \& de Vargas Mores, G. (2018). Scientific development of smart farming technologies and their application in Brazil. Information Processing in Agriculture, 5(1), 21-32. doi:10.1016/j.inpa.2017.12.002

Pucci, J. (2019, Nov 27). Precision Application Asia Moves to Increase Ag Tech Access in Southeast Asia. Precision Agriculture. Retrieved from: https://www.precisionag.com/in-field-technologies/precision-applicationasia-moves-to-increase-ag-tech-access-in-southeast-asia/

Rose, D., \& Chivers, C.-A. (2020). The fourth agricultural revolution is coming - but who will really benefit? The Conversation. Retrieved from: https://theconversation.com/the-fourth-agricultural-revolution-is-comingbut-who-will-really-benefit-145810

Rose, D. C., Wheeler, R., Winter, M., Lobley, M., \& Chivers, C.-A. (2021). Agriculture 4.0: Making it work for people, production, and the planet. Land Use Policy, 100, 104933. doi:10.1016/j.landusepol.2020.104933

Santiteerakul, S., Sopadang, A., Tippayawong, K. Y., \& Tamvimol, K. (2020). The Role of Smart Technology in Sustainable Agriculture: A Case Study of Wangree Plant Factory. Sustainability, 12(11), 4640. doi:10.3390/ su12114640

Sharon, A. (2020). Smart Agriculture the Way Forward in Malaysia. Retrieved from: https://opengovasia.com/ smart-agriculture-the-way-forward-in-malaysia/

Shell LiveWIRE Brunei. (2019). Shell LiveWIRE Brunei launches agropreneur programme. Retrieved from: https://www.livewire.shell/what-is-shell-livewire/news/shell-livewire-brunei-launches-agropreneur-programme. html

Sundmaeker, H., Verdouw, C., Wolfert, S., \& Pérez, F. L. (2016). Internet of food and farm 2020. In O. Vermesan $\&$ P. Friess (Eds.), Digitising the industry: internet of things connecting physical, digital and virtual worlds. River Publishers.

United Nations. (2020). Take Action for the Sustainable Development Goals. Retrieved from: https://www.un.org/ sustainabledevelopment/sustainable-development-goals/

United Nations General Assembly. (1987). Report of the World Commission on Environment and Development: Our common future. Transmitted to the General Assembly as an Annex to Document A/42/427 - Development and International Co-operation: Environment. Retrieved from: https://www.un.org/en/sustainability/

Viviano, F. (2017). This tiny country feeds the world: The Netherlands has become an agricultural giant by showing what the future of farming could look like. National Geographic. Retrieved from https://www.nationalgeographic. com/magazine/2017/09/holland-agriculture-sustainable-farming/

Wallace, R. (2016, June). Big Farms Make Big Flu: Dispatches on Infectious Disease, Agribusiness, and the Nature of Science. Monthly Review. Retrieved from: https://monthlyreview.org/product/big_farms_make_big_flu/

Walter, A., Finger, R., Huber, R., \& Buchmann, N. (2017). Opinion: Smart farming is key to developing sustainable agriculture. Proceedings of the National Academy of Sciences of the United States of America, 114(24), 6148-6150. doi:10.1073/pnas.1707462114 PMID:28611194

Wong, A. (2020). Agrome IQ launches Brunei's first online marketplace for farmers. Biz Brunei. Retrieved from https://www.bizbrunei.com/2020/04/agrome-iq-launches-bruneis-first-online-marketplace-for-farmers/

World Bank. (2016). Transforming Vietnamese Agriculture: Gaining More from Less: The share of primary agriculture in gross domestic product (GDP) will decline, yet the share of the broader agro-food complex will not. Retrieved from: https://documents1.worldbank.org/curated/en/116761474894023632/pdf/108510-WPPUBLIC.pdf 
Zimmermann, R., \& Ferreira, , L.M., \& Carrizo Moreira, A. (2016). The influence of supply chain on the innovation process: A systematic literature review. Supply Chain Management, 21(3), 289-304. doi:10.1108/ SCM-07-2015-0266

Siti Fatimahwati Pehin Dato Musa is a Lecturer in UBD School of Business and Economics, Universiti Brunei Darussalam. She has a PhD in Agricultural Economics and Rural Development from Newcastle University, United Kingdom. She is a recipient of several University grants and welcomes research collaboration in the areas of food security and sustainability, youth and agriculture, youth unemployment, agritourism and rentier economies. She has published a book entitled Inspiring Agriprenuers of Brunei; several book chapters in Springer and Emerald and in international journals pertaining to issues on youth unemployment, youth in agriculture and agribusiness, food security and agritourism.

Khairul Hidayatullah Basir is an assistant lecturer at the Faculty of Islamic Economics and Finance, Universiti Islam Sultan Sharif Ali. His research interest lies in the socio-economic development, particularly in the areas of agriculture and resource economics, youth unemployment and entrepreneurship, and Islamic social finance. He has presented papers at conferences in Australia, Brunei, Malaysia, Philippines, Indonesia, and Thailand. To date, he has successfully published two books and written in a number of journal articles and book chapters. He has acted as ad-hoc peer reviewer for Scopus-indexed journals. Khairul completed his undergraduate studies at the University of Brunei Darussalam, where he earned a B.A. (Hons) in Economics and minored in Islamic Banking and Finance. He holds a Master's degree in Development Studies from the University of Melbourne, Australia and went to the University of Oxford, UK for the Global Mobility Programme where he was awarded Global Mobility Grant University of Melbourne.

Edna Luah is a mentor at Brunei Mentors for Entrepreneurs Network and at AgroBIZ, Shell LiveWIRE Brunei. She is also currently pursuing her Master of Government at Universiti of Brunei Darussalam. Her research interest includes societal inclusion through agribusiness, agrotechnology and smart farming. 